\title{
Accuracy of English Pronoun Use among Malaysian Esl 5-6 Year Old Children and Teaching Implications in the Malaysian Pre-School Education Context
}

\author{
Arshad Abd Samad ${ }^{a}$, Wong Bee Enga, Nurul Iman Arshad ${ }^{\mathrm{b}}$, Kaaminy Kalpany $^{\mathrm{c}}$ \\ ${ }^{a}$ Universiti Putra Malaysia, Selangor, Malaysia \\ ${ }^{b}$ HELP University, Kuala Lumpur, Malaysia \\ ${ }^{\mathrm{c}}$ Sultan Idris Education University, Perak, Malaysia \\ Corresponding e-mail: arshad@upm.edu.my
}

\begin{abstract}
The use of pronouns among young children is an interesting phenomenon to examine due to the psychological connections that can be made between pronouns and the developing concept of ego and self among young children. In a learning English as a Second Language (ESL) situation, however, the acquisition of pronouns may be influenced by other factors such as exposure to the forms as well as the students' first language. This largely descriptive study examines the acquisition of the English pronouns among forty 5 to 6 year old Malaysian ESL pre-schoolers. The children in the study were presented with 33 drawings to assess their familiarity with subjective, objective, possessive and reflexive English pronouns. For each drawing, the children were required to select the correct pronoun from three pronouns that were used in a sentence to describe the drawing. This study will report on accuracy rates for each pronoun, assuming that high accuracy rates indicate a more complete acquisition of the pronoun. Data obtained will be compared to acquisition sequences in the literature. Error forms will also be identified. Finally, some initial suggestions will be made on teaching English pronouns to children whose first language is not English in the context of recent teaching initiatives conducted in Malaysia.
\end{abstract}

Keywords: $\quad$ ESL, Acquisition sequence, Pronouns, Language Development, Language Teaching in Malaysia

\section{INTRODUCTION}

The knowledge of a second language that very young children can demonstrate can provide important insights into how the second language should be presented in the classroom. Language structures that are acquired early can inform educators on factors that can impact on the rate of acquisition of language. Second language acquisition studies have carefully observed how children acquire the second language in a target language environment. The Malaysian context, however, may not always provide second language environments where the target language is often used, encouraged, or even necessary. Instead, in many situations and for many families in Malaysia, English language is a foreign language with limited opportunities for use. The teaching of languages in Malaysian kindergartens exposes children to at least two languages including English and can cause some confusion amongst the children if the same teacher is involved (Abdullah et al., 2015). In such situations, the full acquisition of the English language may be difficult and fossilization of inaccurate forms may also occur. Formal education, therefore, provides an important environment where students can be systematically exposed to a second language.

Pronouns are chosen as the object of this study because they represent a very structured language sub system in the English language and convey various meanings and concepts. There are eight English pronouns (I, we, she, he, it, they, you, and plural you) that take various forms based on their role and meaning in a sentence (e.g. subject, object, number, person, gender, possession and reflexivity). In learning a second language, Rispoli (2005) believes that young children may have complete 
mastery over some forms but only a vague understanding of others. Similarly, Wong and Liu (2008) contend that number and person are easier concepts to master compared to case and should therefore be taught earlier. These situations provide the opportunity to examine the relative acquisition of the various pronoun forms as well as possible difficulties that children encounter.

Additionally, some English pronouns - most notably the objective possessive pronouns (e.g. mine, his, hers) - do not have an equivalent in most of the native languages of children in Malaysia. A study of this nature among young children at this age will also allow for the researcher to examine whether inaccurate forms are introduced early into their developing language systems and subsequently preventive measures can be taken to avoid fossilization of the forms.

Various studies have been done on the acquisition of English pronouns (e.g. Cruttenden, 1977; Morehead \& Ingram, 1973; Morgenstern, 2012; Rispoli, 2005; Waterman \& Shatz, 1982). However, the majority of these studies have been on children acquiring their first language. Based on these studies, Owens Jr (2008) provides an approximate time frame for acquiring this linguistic structure among young children as in Table 1:

Table 1. Approximate sequence of acquisition of pronouns.

\begin{tabular}{|c|c|}
\hline $\begin{array}{l}\text { Age in } \\
\text { Months }\end{array}$ & Pronouns \\
\hline $12-26$ & I, it (subjective and objective) \\
\hline $27-30$ & My, me, mine, you \\
\hline $31-34$ & Your, she, he, yours, we \\
\hline $35-40$ & They, us, hers, his, them, her \\
\hline $41-46$ & $\begin{array}{l}\text { Its, our, him, myself, yourself, ours, their, } \\
\text { theirs }\end{array}$ \\
\hline $47+$ & $\begin{array}{l}\text { Herself, himself, itself, ourselves, yourselves, } \\
\text { themselves }\end{array}$ \\
\hline
\end{tabular}

Sources: Adapted from Haas \& Owens (1985); Huxley (1970); Morehead \& Ingram (1973); Waterman \& Shatz (1982); and Wells (1985).

Charney (1980) notes three theories that may have an influence on the proposed acquisition sequence above. These three theories - the person referring, speech-role referring, and person-in-speech-rolereferring theories - can be analysed according to observed difficulties children face in acquiring pronouns. In the person-referring theory, children treat some pronouns as if the pronoun were some sort of name. This theory explains pronoun reversals such as using the second person pronoun (i.e. you) to refer to the first person (i.e. $I$ ) which is sometimes observed in a child's developing language system. Although Morgenstern (2012) considers pronoun reversals "a minor phenomenon, and quite rare", she notes that "it does seem to play a significant role in the mastery of the pronominal system" (p.58). It is also noted pronominal reversal is frequently observed in language disorders and physical disabilities. Fraiberg and Adelson (1977), for example, point to instances where blind children capable in all other respects, often reversed pronouns well into age five, which they attribute to the difficulties of forming a concept of self without the visual modality.

According to the speech-role referring theory, the child is able to correctly understand the role of pronouns according to who is using the pronouns in the discourse. Therefore, this theory posits that children need to have a non-egocentric view that allows for processing pronouns according to this type of information. Finally, in the person-in-speech role theory which Charney (1980) subscribes to, only pronouns that are relevant to the child are understood by the child. Therefore, the child may be able to use the pronoun I correctly to refer to himself but may not understand why $I$ is also used by someone else when he speaks about himself.

The objective of this research is to examine the use of English language pronouns among young children. More specifically, it intends to document whether the acquisition of pronouns occurs in any specific sequence or pattern as well as document specific problems that young children face in acquiring English pronouns. It is hypothesized that the acquisition of pronouns show a similar pattern as described by Owens Jr (2008) earlier, but may vary due to various factors including the first language of the children. Similarly, some of the problems that children face as described earlier, may also be experienced by Malaysian children learning a second language. Pronoun error forms common to the children will therefore be identified. Finally, the study will suggest ways to introduce pronouns to young children based on the findings.

The research questions of the study addressed in this paper are:

1) What are the English language pronouns that are observed to be used by young children (5-6 years old) in Malaysia?

2) What non-standard forms of English language pronouns are used by young children in Malaysia?

3) Does a pattern emerge in the accurate use of the different kinds of English language pronouns among young children in Malaysia. 


\section{METHODOLOGY}

This study is a quantitative study that employs frequency data in the form of student response to a paper and pencil task complemented by data obtained through interviews and checklists. Forty 5 to 6 year old children from two kindergartens in the state of Selangor and Perak were involved in this study. Both kindergartens were in university campuses and were designated as research or experimental kindergartens by their respective universities and hence allowed easy access to the researchers

The children in the study were required to respond to a 33 item multiple choice question task and were observed by their teachers on the use of English pronouns for a period of two weeks. A follow up discussion was also conducted with the teachers.

\subsection{Respondents}

The forty respondents in the study had varying levels of English language proficiency. They were, however, mostly children of university academic and support staff and were attending the kindergartens at two universities in the states of Selangor and Perak.

\subsection{Pronouns}

In this study, only the following pronouns in Table 2 were examined. Subject, object and possessive pronouns refer to the nominative, accusative and genitive cases respectively. Both the possessive adjectives and the reflexive pronouns are also included in the study because of their close connection to the pronoun forms and the meanings they indicate. In addition to case and type of pronoun, the study also examined how accurately the respondents used the pronouns to indicate person.

Table 2. Pronouns examined in study.

\begin{tabular}{llllll}
\hline Person & $\begin{array}{l}\text { Subj } \\
\text { Pro. }\end{array}$ & $\begin{array}{l}\text { Poss } \\
\text { Adj }\end{array}$ & $\begin{array}{l}\text { Poss } \\
\text { Pro. }\end{array}$ & $\begin{array}{l}\text { Reflexive } \\
\text { Pronouns }\end{array}$ & $\begin{array}{l}\text { Obj } \\
\text { Pro. }\end{array}$ \\
\hline \multicolumn{7}{c}{ 1st } & I & My & mine & myself & me \\
2nd & you & Your & yours & yourself & you \\
3rd (m) & he & His & his & himself & him \\
\hline
\end{tabular}

Table 2. Cont.

\begin{tabular}{llllll}
\hline 3rd (f) & she & Her & hers & herself & her \\
3rd (In.) & it & its & its & Itself & it \\
\hline
\end{tabular}

Table 2. Cont.

\begin{tabular}{llllll} 
& & \multicolumn{2}{c}{ Plural Forms } \\
1st & we & our & ours & Ourselves us \\
2nd & you & your & yours & Yourselves you \\
3rd & they & their & theirs & Themselves & them \\
\hline
\end{tabular}

Note: $\mathrm{m}=$ male, $\mathrm{f}=$ female, In.=Inanimate

Pronoun forms that were considered too ambiguous such as the $2^{\text {nd }}$ person plural form and several $3^{\text {rd }}$ person inanimate forms were excluded from the study as seen in the pronouns that are crossed out in Table 2.

\subsection{Instruments}

Three instruments were used to collect data in this study. The first was a multiple choice question task which was administered to the forty children. The second was a checklist to be used during teacher observations. Teachers were also interviewed in order to obtain a general reaction to the extent to which students were familiar with pronoun use as well as to elicit suggestions on how pronouns can be taught to the children. At the time of writing this paper, however, interview data had not been completely collected.

\subsubsection{The multiple choice question task}

A multiple choice question task was used in order to obtain information regarding pronoun use among children within the time constraints of the study. The teachers assisted in reading out the sentence and the options provided in order to better ensure that the children understood the task. The task was also conducted in the classroom during regular class sessions in order to avoid any sense of test anxiety. The multiple choice question task consisted of 33 items intended to elicit the children's knowledge or familiarity of pronouns. Each item consisted of a sentence containing a blank which the children had to fill by circling one of three pronouns provided. Each sentence was illustrated to help children better understand its meaning.

The three options for each sentence consist of the correct answer or the key as well as two other options that are similar in person reference to the key. Some sentences contained options that are nonsense pronouns such as hisself. This is done to anticipate errors in pronouns as well as error forms that students may make. Figure 1 is an example of 
sentences, the options in parentheses as well as their corresponding drawings.

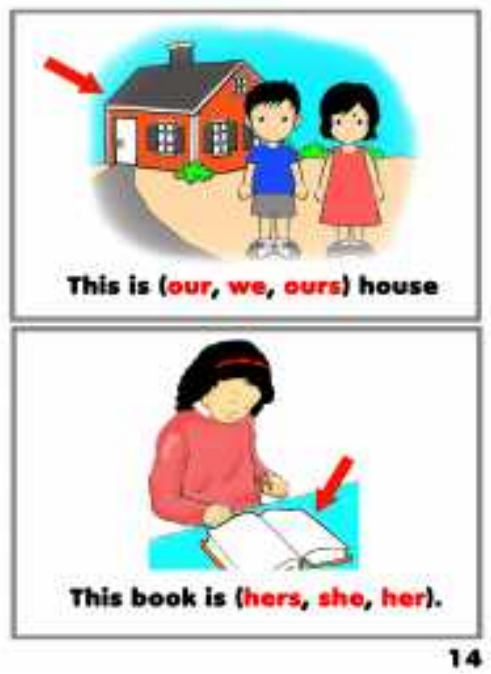

Figure 1. Sample page from pronoun selection task

All sentences were printed in a booklet and given to each child. Teachers were instructed to read the sentences and the options to the children and assist the children in circling their preferred response.

\subsubsection{Teacher observations and interviews}

The major goal of the non-participant teacher observation was to determine the kinds of pronouns used by the children. The observation was conducted over a period of 10 school days or two weeks and a checklist was used to indicate whenever an English language pronoun was used. Teachers were instructed to take note of pronoun use only in natural situations and not when they were using pronouns while reading texts containing pronouns or when the lesson focussed on pronouns. As the observations required intensive teacher involvement, only 15 children from the two kindergartens were observed.

Interviews were conducted after the multiple choice question tasks and the teacher observations. Teachers were asked to identify error forms that they noticed throughout the duration of the study and provide a general assessment of whether they thought the students were able to use the pronoun forms correctly. Their responses regarding the teaching of English to kindergarteners were also elicited.

\subsection{Data Analysis}

Based on the data obtained through the three forms of data collection in this study, a descriptive analysis is provided. Accuracy rates based on the multiple choice item task were calculated and pronouns and pronoun categories were ranked according to percentage of correct responses. Errors made by the respondents and identified especially through the checklist and the teacher interviews were also noted and discussed.

\section{RESULTS}

\subsection{Acquisition of Pronouns}

The acquisition of pronouns among children is discussed in terms of accuracy rates in the multiple choice item tasks, the checklist during teacher observations as well as the interviews with teachers.

\subsubsection{Accuracy Rates}

The children's accuracy rates according to individual pronouns, case as well as person reference are reported in the following tables.

In Table 3, the pronouns that were correctly chosen by 50 percent or more of the children are ranked in order of accuracy.

Table 3. Pronoun rank according to accuracy rates

\begin{tabular}{lllc}
\hline Rank & Type & Pronoun & $\begin{array}{c}\text { Percent } \\
\text { correct }\end{array}$ \\
\hline 1 & 1st per. ref. (sg) & Myself & 85 \\
2 & 3rd per. subj. & She & 65 \\
3 & 1st per. obj. & Me & 60 \\
4 & 3rd per. obj. & Them & 57.5 \\
5 & 1st per. poss adj & My & 55.8 \\
& 2nd per. subj. & You & 55.8 \\
7 & 1st per. poss (pl) & Ours & 52.5 \\
8 & 1st per. subj. & I & 50 \\
& 1st per. ref. (pl) & Ourselves & 50 \\
& 2nd per. poss obj. & Yours & 50 \\
& 3rd per. obj. (sg m) & Him & 50 \\
& 3rd per. obj. (sg f) & Her & 50 \\
& 3rd per. ref. (pl) & Themselves & 50 \\
\hline
\end{tabular}

Note: per.=person, subj.=subject, obj.=object, poss= possessive, $\mathrm{pl}=$ plural, $\mathrm{sg}=$ singular, $\mathrm{m}=$ male $\mathrm{f}=$ female, adj=adjective 
From the list of pronouns in Table 3, it is noted that only 13 pronouns were correctly selected by 50 percent or more of the children.

In Table 4, pronouns were grouped according to case (nominative, accusative or genitive) or kind (possessive adjective or reflexive) and ranked based on accuracy of responses.

Table 4. Pronoun case and type rank according to average accuracy rates

\begin{tabular}{lllc}
\hline Rank & Case & Pronouns & $\begin{array}{c}\text { Percent } \\
\text { correct }\end{array}$ \\
\hline 1 & Subj. (Nom.) & $\begin{array}{l}\text { I, you, he, she, we, } \\
\text { they } \\
\text { Me, you, him, her, } \\
25.4\end{array}$ & 51.5 \\
3 & Obj. (Acc.) & $\begin{array}{l}\text { us, them } \\
\text { Myself, yourself, } \\
\text { himself, herself, } \\
\text { themselves }\end{array}$ & 49.4 \\
4 & Reflexive & $\begin{array}{l}\text { Mine, yours, his, } \\
\text { hers, theirs } \\
\text { Py, your, his, her, }\end{array}$ & 43.7 \\
5 & Poss. Adj. & $\begin{array}{l}\text { Myen } \\
\text { their }\end{array}$ & \\
\hline
\end{tabular}

Table 4 clearly shows that the Nominative and Accusative cases seem to be more familiar with the children as both had accuracy rates of more than 50 percent.

In Table 5, pronouns were grouped according to person reference and the percentage of correct responses for each group was calculated and ranked.

Table 5. Pronoun person reference rank according to average accuracy rates

\begin{tabular}{lllc}
\hline Rank & Person & Pronouns & $\begin{array}{c}\text { Percent } \\
\text { correct }\end{array}$ \\
\hline 1 & 1st per. (sg) & $\begin{array}{l}\text { I, me, my, mine, } \\
\text { myself } \\
\text { they, their, them, } \\
\text { theirs, themselves } \\
\text { we, us, our, ours, } \\
\text { ourselves } \\
\text { you, your, yours, }\end{array}$ & 48.8 \\
3 & 3rd per. (pl) & 46.5 \\
4 & 1st per. (pl) & $\begin{array}{l}\text { you, yourself } \\
\text { 2he, her, hers, her, } \\
\text { herself } \\
\text { he, his, him, his, } \\
\text { himself }\end{array}$ & 43.3 \\
6 & 3rd per. (sg, f) & 39.5 \\
\hline
\end{tabular}

From Table 5, we can see that the 1st person singular reference is the most accurately used with a 57.6 percent accuracy rate. This is followed by the 3rd person plural, 1st person plural and 2nd person pronoun reference.

\subsubsection{Pronoun use according to teacher observations and interviews with teachers}

From the checklists used in the observations, it was noted that subjective pronouns, especially $I$ and you followed by he and she were the most commonly used. Reflexives as well as possessive adjectives were least frequently used. Interestingly, the reflexive pronoun myself was reported to be used more frequently than other reflexive pronouns, many of which were not used at all.

Teacher interviews were especially useful in identifying specific examples of errors in the use of pronouns as well as other information relevant to the study. These error forms are reported in the next section of this paper. Additionally, the interviews also revealed that the children often avoided the use of pronouns by using names instead. This is a common cultural practice especially at a young age even when referring to one's own self.

\subsection{Error Forms}

All three instruments used in this study can potentially elicit error forms used by students. However, at the time of writing this paper, only error forms indicated by the teachers during the observations and the interview have been analysed and can be presented and discussed.

During the interviews, teachers from the two kindergartens mentioned specific instances of errors. In one example, the sentence Me want to go is used instead of I want to go. It is not clear why this error is made although one can theorise that the student may believe that first person pronouns - especially $I$, me, my and mine - can be treated as a name referring to the first person and is also interchangeable.

Other errors that were reported include My one is at home when talking about a doll, and the response of $m e$... me, when asked whose book is this, and You table when asked whose table is this? One of the teachers also noted that the students preferred to use the names of their friends instead of pronouns. 


\section{DISCUSSION}

Based on the results as reported in Tables 3, 4, and 5 as well as the checklists and error forms, some tentative findings can be derived.

Firstly, there is indication that first person pronouns, especially I and me, are acquired generally early relative to other pronouns. Although none of these three pronouns occupy the most accurately used pronoun position according to the multiple choice response task, nevertheless first person pronouns as a group are generally accurately used by many of the students. A second pronoun that has a relatively high accuracy rate is the 2 nd person pronoun you. This is observed not so much in the accuracy of responses in the multiple choice question task, but more so through feedback from the checklist and the teacher observations where both you and I are reported as commonly used pronouns which some teachers in the study refer to as "common" pronouns.

The students' greater familiarity to and accuracy of the use of the pronouns $I$ and you compared to other pronouns is not surprising. Rispoli (2005, p. 95) argues that acquisition of first and second person differs from that of third person as third person can be replaced by a noun-head whereas the former two cannot. Hence, while the pronoun he in He lives here can be replaced by The boy, it is not possible to replace the pronouns you and $I$ in the sentences You live here and I live here respectively. Therefore, it can be argued that there is greater markedness with the pronouns $I$ and you as they are not easily replaced or substituted by other words.

In terms of accuracy rates for individual pronouns, it cannot be ignored that the reflexive pronoun myself occupies the most accurately used pronoun position in the list. Similarly, it is also noted as a commonly used pronoun by many teachers in the teacher observation checklist. It is difficult to explain the reason for its prominence compared to other reflexive pronouns or even to other pronouns in general. Interestingly, however, the National Curriculum for Kindergartens in Malaysia which emphasises a thematic approach with Myself as one of the seven themes of the curriculum.

Finally, the results obtained in Table 3 are interesting for a particular reason. The tendency to use the 1st person singular, 3rd person plural, 1st person plural and 2nd person pronouns accurately in that order may reflect the nature of interaction among young children that takes place in kindergartens. During visits to the kindergarten, the children were seen to play and interact in groups and this may explain the familiarity with the use of these sets of pronouns compared to third person singular male (he) and female (she) pronouns. This possibility, however, is once again tentative and should be given further attention.

\section{CONCLUSIONS}

A major conclusion that can be made from the results of this study is that more "common" pronouns such as $I$, you, and me are acquired early among Malaysian children learning English as a second language. The implication of this is that intervention must be provided to children at this age who are not yet able to accurately use these pronouns.

Secondly, there is indication from the data that children focus on their self and acquire pronouns that refer to the first person earlier than those that refer to others. This finding is not surprising as it reflects the developing ego, self-awareness or selfidentity of the child. From a teaching perspective, this may give credence to the grouping of pronouns according to person reference rather than more common language related concepts such as case, possessive adjectives and reflexives.

Finally, the presentation of pronouns to children should also consider groupings that can address specific issues or concerns as observed in this study. For example, as the students were observed to use names more than pronouns, the introduction of third person singular pronouns such as he and she should be done in situations where the discourse will include names followed by the relevant pronouns. Similarly, the specific errors made such as my one and me instead of $I$ as indicated by the reports can be addressed through enhancement of the correct forms through oral emphasis or gestures during teacher-led play or demonstrations.

\section{ACKNOWLEDGEMENTS}

This study was funded by a one-year grant from the National Children's Development Research Centre (NCDRC) at Sultan Idris Education University, Perak, Malaysia. 


\section{REFERENCES}

Abdullah, A. C., Tan Kok Eng, Chitra K.M.

Krishnan Adiyodi, Yeoh Phaik Kin, \& Regina Joseph Cyril. (2015). Chapter 4: Preschool. In English Language Reform in Malaysia: The Roadmap 2015-2025. Kuala Lumpur: Ministry of Education, Malaysia.

Charney, R. (1980). Speech roles and the development of personal pronouns. Journal of Child Language, 7, 509-528.

Cruttenden, A. (1977). The acquisition of personal pronouns and language 'simplification'. Language and Speech, 20, 3, 191-197.

Fraiberg, S. \& Adelson, E. (1977). Selfrepresentation in language and play. In, S. Fraiberg, Insights from the blind (248-270). New York: Basic Books, Inc.

Huxley, R. (1970). The development of the correct use of the subject personal pronouns in two children. In Flores d'Arcais, G. B., and Levelt, W. J. M. (eds.), Advances in Psycholinguistics (New York).

Morehead, D. M., \& Ingram, D. (1973). The development of base syntax in normal and linguistically deviant children. Journal of Speech, Language, and Hearing Research, 16(3), 330-352.

Morgenstern, A. (2012). The self as Other: Selfwords and pronominal reversals in language acquisition. In Lorda \& Zabalbeascoa. Spaces of Polyphony (57-72). New York: John Benjamins Publishing.

Owens Jr., J. E. (2008). Language Development: An Introduction. New York: Allyn \& Bacon.

Rispoli, M. (2005). When children reach beyond their grasp: Why some children make pronoun case errors and others don't. Journal of Child Language, 32, 93-116

Waterman, P. \& Shatz, M. (1982). The acquisition of personal pronouns and proper names by an identical twin pair. Journal of Speech, Language, and Hearing Research. 25, 149-154.

Wells, G. (1985). Language development in the preschool years. Cambridge, England: Cambridge University Press.

Wong, B. E. \& Liu, J. C. (2008). The Acquisition of Gender, Number and Case in English Personal Pronouns. In Jacobson, R. (Ed.) The Pulse of a Malaysian University (101-119). New York: Peter Lang.

Yet another person's thoughts. http://dervine7. blogspot.my/2011/02/personal-pronouns.html. Retrieved 18 July 2016. 